\title{
A MIXTURE FRAILTY MODEL FOR MAINTAINABILITY ANALYSIS OF MECHANICAL COMPONENTS: A CASE STUDY
}

\author{
Rezgar Zaki ${ }^{1}$, Abbas Barabadi ${ }^{1}$, Ali Nouri Qarahasanlou ${ }^{2}$, A.H.S. Garmabaki ${ }^{3}$ \\ ${ }^{1}$ Department of Technology and Safety, UiT The Arctic University of Norway, Tromsø, Norway \\ ${ }^{2}$ Faculty of Mining Eng., Petroleum and Geophysics, Shahrood University of Technology, Shahrood, lran \\ ${ }^{3}$ Division of Operation and Maintenance Engineering, Luleå University of Technology, Luleå, Sweden
}

Abstract: Knowing the maintainability of a component or a system means that repair resource allocations, such as spare part procurement and maintenance training, can be planned and optimized more effectively. Repair data are often collected from multiple and distributed units in different operational conditions, which can introduce heterogeneity into the data. Part of such heterogeneity can be explained and isolated by the observable covariates, whose values and the way that they can affect the item's maintainability are known. However, some factors which may affect maintainability are typically unknown (unobserved covariates), leading to unobserved heterogeneity. Nevertheless, many researchers have ignored the effect of observed and un-observed covariates, and this may lead to erroneous model selection, as well as wrong conclusions and decisions. Moreover, many authors have simplified their analysis by considering a complex system as a single item. In these studies, the assumption is that all repair data represent an identical repair process for the item. In practice, mechanical systems are composed of multiple parts, with various failure mechanisms, which need different repair processes (repair modes) to return to the operational phase; classical distribution, such as lognormal, which is only a function of time, may not be able to model such complexity. The paper utilizes the Mixture Frailty Model (MFM) in the presence of some specific observed or unobserved covariates to predict maintainability more precisely. Mixture Frailty Models can model the effect of observed and unobserved covariates, as well as identifying different repair processes in the repair dataset. The application of the proposed model is demonstrated by a case study.

Keywords: Mixture Weibull, Failure model, Repair process, Covariates, Repair time, Maintainability, Frailty model 


\section{INTRODUCTION}

In today's society, we are strongly dependent on the optimal functioning of complex technical systems, such as communication networks, railways, power plant control systems, aircraft, mining, the oil and gas industry, etc. As these systems fail, they should be repaired as soon as possible in a safe manner, to reduce the consequences of the failure, including production loss, safety and health effects. To achieve such a goal, the system should be designed for maintainability.

Maintainability is a design factor that decides the degree to which a product allows safe, quick and easy replacement of its component parts. Design for maintainability refers to designing the system to find the optimum balance between capital cost and ongoing maintenance cost (Barabadi et al. 2010; Tortorella 2015; Tsarouhas 2015; Garmabaki et al. 2016a; Gharahasanlou et al. 2017; Kumar et al. 2017; Aggarwal et al. 2017). Design for maintainability needs to consider human ergonomics, logistics management, design layout, the level of experience and training of maintenance personnel and so on (Knezevic 1993; Naseri and Barabady 2016). Ease of access, standardization of equipment - both internally and between companies - skill levels to maintain equipment, organization culture, service delivery infrastructure, etc. are some of the main elements of maintainability. Maintainability performance is defined as "the ability of an item under given conditions of use, to be retained in, or restored to, a state in which it can perform a required function, when maintenance is performed under given conditions and using stated procedures and resources" (Rausand and Høyland 2004). 'Item' here refers to a system, component, or subsystem (Barabadi and Markeset 2011; Furuly et al. 2013). Existing studies regarding the maintainability analysis of historical data have ignored the effect of observed and unobserved covariates (risk factors). Moreover, many authors have simplified their analysis by considering a complex system as a single item, then modeling the repair data using a classical distribution, mostly lognormal (Tsarouhas et al. 2009; Hoseinie et al. 2011; Tsarouhas and Arvanitoyannis 2012; Wang 2014; Sellitto and Brusius Jr 2017; Tsarouhas 2018). However, the relationship between the elements of maintainability is complex and mediated by many influence factors such as ambient temperature, human factors, and dissimilarity in personality or skill level between maintenance crews, etc. As a main part of maintainability, logistics and spare parts constitute a complex activity that is time- and location-dependent (Wijaya and Lundberg 2012; Ahmadzadeh and Lundberg 2014; Barabadi et al. 2015, 2016; Gudmestad and Markeset 2015; Ayele et al. 2016). Hence, a single distribution, such as lognormal, which is only a function of time, is not able to capture such complexities.

Recently, some attempts have been made to relate maintainability to both historical repair data and operational conditions as observed covariates. Gao et al. (2010) developed the proportional repair model (PRM), based on the proportional hazard model (PHM), which is the most widely used in reliability analysis, when considering the effect of operational conditions (Kumar and Klefsjö 1994; Rosen and Tanner 1999; Gao et al. 2010; Van Horenbeek et al. 2010; Barabadi et al. 2011). An important alternative to the PHM is the accelerated failure time model (AFT). The AFT model accounts for the effects of the covariates directly on survival times, instead of the hazard rate as in the PHM (Patel et al. 2006; Barabadi et al. 2011; Garmabaki et al. 2016c; Ayele et al. 2018). 
The PRM is a product of the baseline repair rate and a functional term incorporating the effects of timeindependent observed covariates. PRMs are only able to model the effect of time-independent observed covariates. In the case of time-dependent covariates, the assumption of proportionality is violated, and the PRM cannot be built. To deal with non-proportionality, Barabadi et al. Barabadi and Markeset (2011) used a stratification approach to model the effect of time-independent covariates. In the stratification approach, the data are categorized based on different levels of time-dependent observed covariates. However, their studies did not consider the effect of unobserved covariates. Unobserved covariates are covariates whose effects on the repair process are typically unknown or whose associated levels during repair time are not available in the repair database (Gimenez et al. 2018). Ignoring the effect of observed and unobserved covariates would lead to significant differences in the estimation of the effects of covariates (Vaupel et al. 1979; Kumar and Klefsjö 1994; Hougaard 1995; Ayele et al. 2016). Observed and unobserved covariates result in observed or unobserved heterogeneity among repair data (Asfaw and Lindqvist 2015). A systematic literature review revealed no articles dealing with the modeling of unobserved covariate effect on the maintainability of items.

Moreover, in these studies, the assumption is that all repair data represent an identical repair process for the item. In reality, mechanical systems are composed of multiple parts, with various failure mechanisms, which need different repair processes (repair modes) to return them to the operational phase. For instance, a gearbox failure may result from individual failures in the gears, bearings, or shafts and include fatigue cracks, teeth breakage, wear, etc. These failure modes may have completely different repair processes and resources. In most of the available databases, the repair data are mixed together under the title, "Repair data for gearbox" (Barabadi et al. 2015; Gharahasanlou et al. 2017). In dealing with such datasets, as mentioned, analysts simplify their analysis by considering such complex datasets as homogeneous, with repair data being represented by an identical repair process. These studies have viewed the historical data as a black box, with no information regarding the repair process and its operational conditions.

According to the discussion, two issues should be considered when modeling the maintainability of an item:

i) The selected model should be able to capture the effect of observed and unobserved covariates on the time of the maintenance, and

ii) As in many cases the repair data are a mix of different repair processes (repair modes), the applied model should be able to isolate different repair modes.

When each repair process is regarded as an independent repair mode with a repair distribution in the presence of some specific observed or un-observed risk factors, then a mixture frailty model (MFM) can be separately constructed to effectively predict maintainability.

An MFM is an extension of the PRM, where unobserved and observed covariates have a multiplicative effect on the repair rate. In MFM, the repair rate of an item is the product of a baseline hazard rate multiplied by two positive functions: an observed and an unobserved covariate function (frailty function). In addition, the MFM has the ability to model different repair modes. The frailty term was introduced by 
Clayton et al. (1978) and Vaupel et al. (1979) in survival analysis in medical science, based on the PHM. Several researchers later used the frailty concept to model the effect of unobserved covariates on the reliability of an item, to describe the influence of unobserved covariates. For example, Slimacek and Lindqvist (2016) used frailty to model the effect of unobservable differences between turbines, as unobserved covariates, on the reliability of wind turbines, using a Poisson process. Giorgio et al. (2014) modeled the failure pattern of a powertrain system in the presence of observed and unobserved heterogeneity, via a joint probability distribution on power law process parameters. Finkelstein (2007) used the frailty model to study the reliability of a system subject to shocks, which occur in accordance with a non-homogeneous Poisson process. He showed that that reliability analysis for a heterogeneous case could differ dramatically from that for a homogeneous setting.

The rest of the paper is organized as follows. In Section 2, the MFM is explained; thereafter, in Section 3 , the application of the proposed model is illustrated by a case study. Finally, Section 4 provides the conclusions.

\section{MiXture Frailty Model (MFM) FOR MAINTAinAbility ANALYSIS}

The repair rate of an item is the rate at which a repair action is performed. It is expressed in terms of the number of repair actions performed and successfully completed per unit of time, by considering timedependent and time-independent observed and unobserved covariates. It can be expressed as follows:

$$
\mu\left(t, z_{i}, z_{j}(t) \mid A\right)=A \mu_{0}(t) \psi(z, z(t) ; P ; \delta)
$$

where $z_{i}$ and $z_{j}(t)$ are time-independent and time-dependent observed covariates $P ; \delta$ are column vectors, consisting of the regression parameters for identified time-independent and time-dependent observed covariates; and $A$ is a random positive quantity, representing the cumulative effect of one or more unobserved covariates.

Here, the repair rate, $\mu\left(\mathrm{t}, \mathrm{z}_{\mathrm{i}}, \mathrm{z}_{\mathrm{j}}(\mathrm{t}) ; A\right)$, consists of three multiplicative factors: $\left.i\right)$ the baseline repair rate $\mu_{0}(t)$, dependent on time alone, which is modeled using appropriate distributions; ii) a positive multiplicative factor, $\psi(z, z(t) ; P ; \delta)$, to describe the function of time-independent and time-dependent observed covariates; and iii) a positive multiplicative factor, A, representing the effect of unobserved covariates. The observed and unobserved covariates can affect the repair rate, so that the actual repair rate, $\mu\left(\mathrm{t}, \mathrm{z}_{\mathrm{i}}, \mathrm{z}_{\mathrm{j}}(\mathrm{t}) ; A\right)$, is either greater (e.g. in the case of poor maintenance) or less (e.g. with better training for operators and maintenance crew) than the baseline repair rate. Here, those items with $A>1$ are said to be less frail, for reasons left unexplained by the observed covariates, and will have an increased repair rate. Those items for which $A<1$ are frailer; hence, given a certain observed covariate pattern, they tend to reduce the repair time. In general, the exponential functional form and gamma distribution (with the mean equal to one and variance of $\theta$ ) are the most commonly used functions for modeling observed and unobserved covariates, respectively (Cha and Finkelstein 2014; Asfaw and Lindqvist 2015; Garmabaki et al. 2016b; Slimacek and Lindqvist 2017). Under these assumptions, the maintainability function can be written as: 


$$
\mathrm{M}\left(t, z_{i}, z_{j}(t) \mid A\right)=1-\exp \left[-\int_{0}^{t} \mu(u \mid A) d u\right]=1-\exp \left[-A \int_{0}^{t} \frac{m(u)}{1-M(u)} d u\right]=1-\left\{1-\mathrm{M}\left(t, z_{i}, z_{j}(t)\right)\right\}^{A}
$$

Because $\mathrm{A}$ is unobservable, it must be integrated out of $\mathrm{M}\left(t, z_{i}, z_{j}(t) \mid A\right)$ to obtain the unconditional maintainability function. When $\mathrm{A}$ is distributed as gamma with mean one and variance $\theta$ :

$$
\mathrm{g}(\mathrm{A})=\frac{A^{\frac{1}{\bar{\theta}}-1} e^{-\frac{A}{\theta}}}{\Gamma\left(\frac{1}{\theta}\right) \theta^{\frac{1}{\theta}}}
$$

Then maintainability becomes:

$$
\mathrm{M}_{\theta}(t)=1-\int_{0}^{\infty}\left\{1-\mathrm{M}\left(t, z_{i}, z_{j}(t)\right)\right\}^{A} \cdot \frac{A^{\frac{1}{\theta}-1} e^{-\frac{A}{\theta}}}{\Gamma\left(\frac{1}{\theta}\right) \theta^{\frac{1}{\theta}}} d A=1-\left[1-\theta \ln \left\{1-\mathrm{M}\left(t, z_{i}, z_{j}(t)\right)\right\}\right]^{-\frac{1}{\theta}}
$$

If the observed covariate follows the exponential function in the presence of $W$ time-independent observed covariates and $M$ time-dependent observed covariates, $\mathrm{M}\left(t, z_{i}, z_{j}(t)\right)$ can be written as:

$$
\mathrm{M}\left(t, z_{i}, z_{j}(t)\right)=1-\left[1-\mathrm{M}_{0}(\mathrm{t})\right]^{\exp \left[\sum_{\mathrm{i}=1}^{\mathrm{W}} \mathrm{p}_{\mathrm{i}} \mathrm{z}_{\mathrm{i}}+\sum_{\mathrm{j}=1}^{\mathrm{M}} \delta_{\mathrm{j}} \mathrm{z}_{\mathrm{j}}(\mathrm{t})\right]}
$$

where $M_{0}(t)$ is the baseline maintainability function dependent only on the time, as follows:

$$
\mathrm{M}_{0}(t)=1-\exp \left[-\int_{0}^{t} \mu_{0}\left(t^{\prime}\right) d t^{\prime}\right]
$$

As mentioned, in reality, the historical repair data are a mix of different repair processes (repair modes); hence, the applied model should be able to isolate different repair modes. If each repair process is regarded as an independent process with an individual, repair distribution that the presence of some specific covariates, then mixture distribution can be used to model the maintainability baseline. Suppose a repair dataset of specific items consists of $N$ repair processes, which require different maintenance tasks and repair actions comprised of several subsidiary tasks of unequal frequency and time duration. Under these conditions, the mixture baseline maintainability function, $\left(M_{0 m}(\mathrm{t})\right)$, can be defined by mixing the $M_{0}(t)$ of the several repair processes as:

$$
M_{0 m}(\mathrm{t})=\sum_{\mathrm{k}=1}^{\mathrm{N}} \gamma_{\mathrm{k}} \cdot M_{0 k}=\sum_{\mathrm{k}=1}^{\mathrm{N}} \gamma_{\mathrm{k}} \cdot\left(1-\exp \left[-\int_{0}^{t} \mu_{k 0}\left(t^{\prime}\right) d t^{\prime}\right]\right)
$$

where $M_{0 k}$ is the baseline maintainability of the $\mathrm{k}^{\text {th }}$ repair process and $\Upsilon_{\mathrm{k}}$ is the proportion of the repair tasks belonging to the $\mathrm{k}^{\text {th }}$ repair process. If the basic principle of the probability dominance, which states that the summation of all of the proportion of $\Upsilon_{\mathrm{k}}$ has to be one therefore $\sum_{k=1}^{N} \gamma_{k}=1$ should hold.

The baseline maintainability function, if the repair rate for all repair processes follows 2-parameter Weibull distribution, is given by: 


$$
M_{0 m}(\mathrm{t})=\sum_{\mathrm{k}=1}^{\mathrm{N}} \gamma_{\mathrm{k}} \cdot\left(1-e^{-\left(\frac{t}{\eta_{\mathrm{k}}}\right)^{\beta_{\mathrm{k}}}}\right)
$$

where $\beta_{\mathrm{k}}$ and $\eta_{\mathrm{k}}$ are the shape parameter and scale parameter of Weibull distribution for the $k^{\text {th }}$ repair process. Likelihood function can be used to estimate the parameters in Eq. (8). The estimation of the maximum likelihood for the given log-likelihood function is demanding. Therefore, some type of iterative algorithms can be employed to approximately estimate the parameters for the mixed distribution.

\section{CASE STUDY}

Figure 1 shows a black diagram for a production line in the Sungun Copper Mine in Iran. In this production line, seven Komatsu HD 325-6 dump trucks work, defined as DT.1 to DT.7. Here, the repair data for all dump trucks are collected through daily repair and operation reports. As these reports are not designed for maintainability analysis, the repair processes are mostly neither well recorded nor detailed. However, based on a discussion with experts, the collected repair dataset is a mixture of different repair processes. In addition, for each repair time, associated observed covariates have been collected through discussion with experts at the mine. Table 1 shows the identified observed covariates and their associated levels. The levels for each covariate are identified, based on the different operational conditions that trucks will experience during their mission time. The maintainability covariates include working shift, weather condition, precipitation, temperature, and number of involved maintenance crews. The shift generally represents a diverse maintenance crew, whose different skills and expertise may affect the maintainability performance of the trucks. In addition, some maintenance tasks can take a long time to complete. In such scenarios, several maintenance crews will work to repair the trucks over a number of shifts. Under these conditions, repair crews need effective communication. Ineffective communication will significantly reduce maintainability, as some jobs need to be repeated or must be double-checked. Hence, the number of maintenance crews working on a truck is considered a maintainability covariate. Moreover, as most of the maintenance is performed outdoors, precipitation is considered a covariate. 


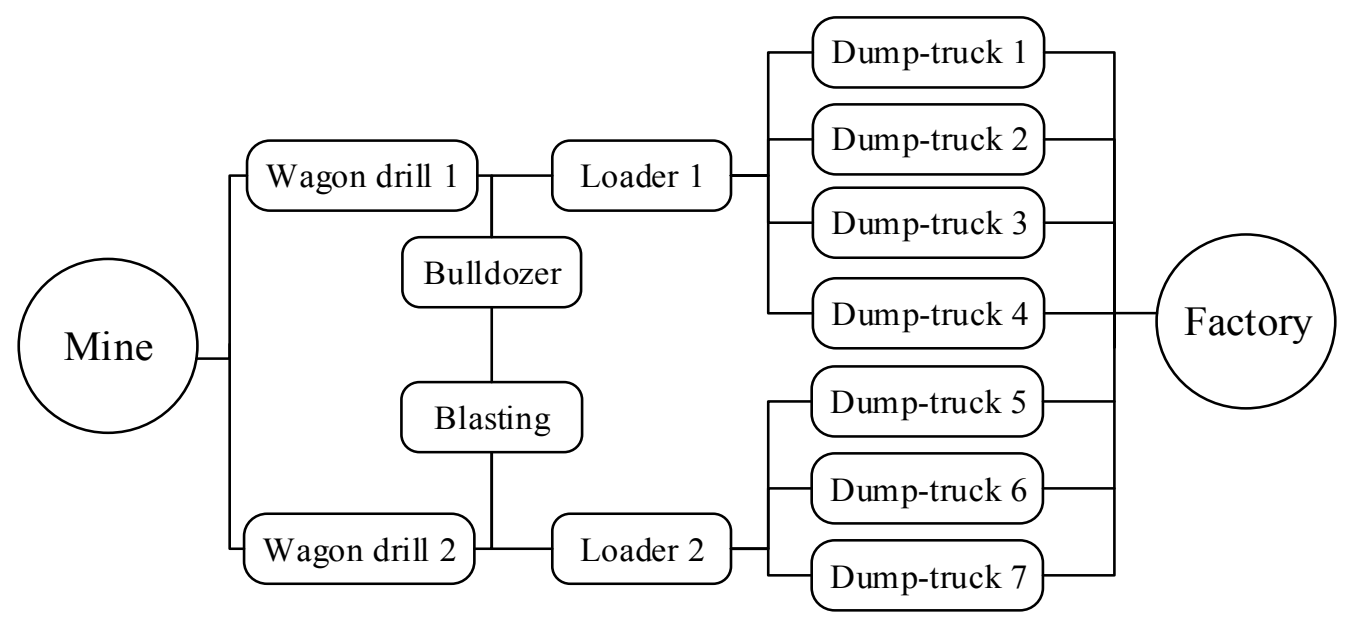

Figure 1: Block diagram for a production line at the Sungun Copper Mine

Table 1: Identified maintainability covariates and their associated levels

\begin{tabular}{|c|c|c|}
\hline Maintainability covariates & Covariate level & Assigned code \\
\hline \multirow{3}{*}{ Working shift $\left(\mathrm{z}_{1}\right)$} & Morning & 1 \\
\cline { 2 - 3 } & Afternoon & 2 \\
\cline { 2 - 3 } & Night & 3 \\
\hline \multirow{4}{*}{ Weather condition $\left(\mathrm{z}_{2}\right)$} & Sunny \& clear & 1 \\
\cline { 2 - 3 } & Semi cloudy & 2 \\
\cline { 2 - 3 } & Overcast & 3 \\
\cline { 2 - 3 } & Dense fog & 4 \\
\hline Precipitation $\left(\mathrm{z}_{3}\right)$ & \multicolumn{2}{|c|}{ Continuous covariate } \\
\hline Temperature $\left(\mathrm{z}_{4}\right)$ & \multicolumn{2}{|c|}{ One } \\
\hline \multirow{2}{*}{ Involved maintenance crew $\left(\mathrm{z}_{5}\right)$} & More than one & 2 \\
\cline { 2 - 3 } & \multicolumn{2}{|c}{} \\
\hline
\end{tabular}

Using the MFM and this assumption that all covariates are time-independent, the maintainability for each component can be estimated. The results of the analysis are shown in Table 2 . Here, the $p$-value of $5 \%$ is considered the upper limit to check the significance of observed and unobserved covariates. This table shows the likelihood ratio (LR), which is used to check whether the unobserved covariate(s) has (have) a significant effect on maintainability. In this case, LR can be written as follows (Garmabaki et al. 2016b):

$$
L R=2\left(\ln L\left(\beta_{k}, \eta_{k}, p_{k}, \gamma_{k}, \theta\right)-\ln \left(\beta_{0 k}, \eta_{0 k}, p_{0 k}, \gamma_{0 k}, 0\right)\right)
$$

Here, $\beta_{0 k}, \eta_{0 k}, p_{0 k}$ and $\gamma_{0 k}$ are estimated parameters under the null hypothesis, where $\theta=0$, which means the unobserved covariate(s) has (have) no significant effect on the maintainability of the trucks. As Table 2 shows, for example for truck DT.7, the baseline maintainability is Mixture 2 Weibull distribution, 
the first population is $43 \%$, with $\beta_{1}=4.189$ and $\eta_{1}=6.249$, while the second population is around $57 \%$, with $\beta_{2}=0.982$ and $\eta_{2}=21.166$. Using these parameters, the baseline mean time to repairs (MTTR) will be equal to 5.7 and 21.3 for Population No. 1 and No. 2, respectively. Moreover, involved maintenance crew $\left(z_{5}\right)$ and precipitation $\left(z_{3}\right)$ have a significant effect on the maintainability of DT.7, with their regression coefficients being equal to -1.872 and -1.187 , respectively. Moreover, the $p$-value associated with the LR of DT.7 is equal to 0.000 , which hints that unobserved covariates have a significant effect on the maintainability of DT.7, with $\theta=9.22$.

Table 2: Estimated parameters of the maintainability performance of selected items

\begin{tabular}{|c|c|c|c|c|c|c|c|c|c|c|}
\hline \multirow{2}{*}{ Truck } & \multicolumn{3}{|l|}{ Observed Covariates } & \multicolumn{3}{|c|}{$\begin{array}{c}\text { Unobserved } \\
\text { Covariates }\end{array}$} & \multirow{2}{*}{\multicolumn{2}{|c|}{ Baseline model }} & \multirow{2}{*}{$\begin{array}{l}\text { Baseline } \\
\text { MTTR }\end{array}$} & \multirow{2}{*}{$\begin{array}{c}\gamma \\
(\%)\end{array}$} \\
\hline & Covariates & $p_{i}$ & $\begin{array}{c}p- \\
\text { value }\end{array}$ & $L R$ & $\begin{array}{c}p- \\
\text { value }\end{array}$ & $\theta$ & & & & \\
\hline \multirow{3}{*}{ DT.1 } & Working shift $\left(\mathrm{z}_{1}\right)$ & -1.370 & 0.001 & \multirow{3}{*}{16.3} & \multirow{3}{*}{0} & \multirow{3}{*}{3.24} & \multirow{3}{*}{ 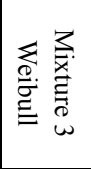 } & $\beta_{1}=2.234 ; \eta_{1}=2.289$ & 2.03 & 19 \\
\hline & \multirow{2}{*}{ Involved maintenance crew $\left(z_{5}\right)$} & \multirow{2}{*}{-1.179} & \multirow{2}{*}{0.001} & & & & & $\beta_{2}=2.845 ; \eta_{2}=6.7054$ & 5.97 & 47 \\
\hline & & & & & & & & $\beta_{3}=0.718 ; \eta_{3}=26.7674$ & 33.1 & 35 \\
\hline & Working shift $\left(\mathrm{z}_{1}\right)$ & -0.751 & 0.005 & \multirow{3}{*}{39.7} & \multirow{3}{*}{0} & \multirow{3}{*}{3.82} & \multirow{3}{*}{ w } & \multirow{3}{*}{$\begin{array}{c}\beta_{1}=1.054 ; \eta_{1}=6.810 ; \gamma_{1} \\
=0.815\end{array}$} & \multirow{3}{*}{6.95} & \multirow{3}{*}{100} \\
\hline DT.2 & Involved maintenance crew $\left(\mathrm{z}_{5}\right)$ & -1.351 & 0.000 & & & & & & & \\
\hline & Precipitation $\left(\mathrm{z}_{3}\right)$ & -0.090 & 0.035 & & & & & & & \\
\hline \multirow{3}{*}{ DT.3 } & Working shift $\left(\mathrm{z}_{1}\right)$ & -3.267 & 0.000 & \multirow{3}{*}{57.1} & \multirow{3}{*}{0} & \multirow{3}{*}{7.59} & \multirow{3}{*}{ 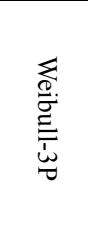 } & \multirow{3}{*}{$\begin{array}{c}\beta_{1}=0.946 ; \eta_{1}=7.886 ; \gamma_{1} \\
=0.925\end{array}$} & \multirow{3}{*}{9.01} & \multirow{3}{*}{100} \\
\hline & Involved maintenance crew $\left(\mathrm{z}_{5}\right)$ & 0.356 & 0.033 & & & & & & & \\
\hline & Precipitation $\left(\mathrm{z}_{3}\right)$ & -0.237 & 0.001 & & & & & & & \\
\hline \multirow{3}{*}{ DT.4 } & Working shift $\left(\mathrm{z}_{1}\right)$ & -1.214 & 0.000 & \multirow{3}{*}{64.2} & & & $\leq 3$ & $\beta_{1}=3.750 ; \eta_{1}=3.980$ & 3.6 & 32 \\
\hline & Jnulud maintanono orous ( ) & 1050 & 0001 & & & 3.08 & 豆 & $\beta_{2}=18.160 ; \eta_{2}=6.624$ & 6.43 & 21 \\
\hline & Involved maintenance crew $\left(z_{5}\right)$ & -1.059 & 0.001 & & & & & $\beta_{2}=1.122 ; \eta_{2}=10.435$ & 10.0 & 47 \\
\hline & Involved maintenance crew $\left(\mathrm{z}_{5}\right)$ & -5.077 & 0.000 & & & & & $\beta_{1}=6.399 ; \eta_{1}=1.752$ & 1.63 & 11 \\
\hline DT.5 & & & & 64.0 & 0 & 11.94 & 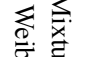 & $\beta_{2}=3.023 ; \eta_{2}=3.402$ & 3.03 & 38 \\
\hline & Weather condition (z) & 0408 & 0004 & & & & $\stackrel{\mathscr{E}}{E} \underset{D}{E}$ & $\beta_{3}=20.828 ; \eta_{3}=6.548$ & 6.38 & 33 \\
\hline & weanter condinon $\left(z_{2}\right)$ & & & & & & & $\beta_{4}=0.683 ; \eta_{4}=72.208$ & 93.6 & 18 \\
\hline & Working shift $\left(\mathrm{z}_{1}\right)$ & -0.485 & 0.094 & & & & & 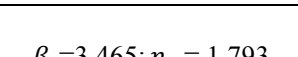 & 165 & 21 \\
\hline & Involved maintenance crew $\left(\mathrm{z}_{5}\right)$ & -2.505 & 0.000 & & & & 赵 & $\rho_{1}-5.405, \eta_{1}-1.193$ & 1.05 & 21 \\
\hline DT.6 & Weather condition $\left(\mathrm{z}_{2}\right)$ & 0.387 & 0.022 & 26.5 & 0 & 2.33 & $\begin{array}{l}E \\
\stackrel{D}{\perp}\end{array}$ & $\beta_{2}=4.965 ; \eta_{2}=3.809$ & 3.5 & 40 \\
\hline & Precipitation $\left(\mathrm{z}_{3}\right)$ & -0.248 & 0.028 & & & & $\stackrel{\mathscr{Q}}{\stackrel{E}{E}}$ & $\beta_{3}=22.331 ; \eta_{3}=6.622$ & 6.5 & 23 \\
\hline & & & & & & & & $\beta_{4}=0.901 ; \eta_{4}=28.634$ & 30.1 & 16 \\
\hline & Precipitation $\left(\mathrm{z}_{3}\right)$ & -1.827 & 0.000 & & & & $\leftleftarrows 3$ & $\beta_{1}=4.189 ; \eta_{1}=6.249$ & 5.7 & 43 \\
\hline DT.7 & Inyolyed maintenance crew (z) & 1187 & 0000 & 41.2 & 0 & 9.22 & 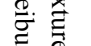 & & & \\
\hline & Involved maintenance crew $\left(z_{5}\right)$ & -1.187 & 0.000 & & & & & $\beta_{2}=0.982 ; \eta_{2}=21.166$ & 21.3 & 57 \\
\hline
\end{tabular}


In the next step, to compare the results of analysis with the traditional model, the data were analyzed by classical distributions. Here, we nominated five distributions, including 3P-Weibull, 2P-Exponential, 1PExponential, 2P-Weibull, and Normal distributions. Thereafter, using goodness of fit test, the best fit distribution for each truck was identified.

For example, Table 3 shows the results of analysis for DT.7 and the goodness of fit test, using three different models. The $A v G O F$ column contains the average values from the Kolmogorov-Smirnov $(G O F)$ test, the $A v P L O T$ column contains the average values from the correlation coefficient (PLOT) test, and the $L K V$ column contains the average values from the Likelihood Value ( $L K V)$ test. As the goodness of fit tests in Table $3(A v G O F, A v P L O T$ and $L K V)$ show the 3P-Weibull with $\beta=1.046 ; \eta=12.836$ and $\gamma=$ 0.877 is the best fit distribution for DT.7. Hence, the maintainability of truck DT.7 can be written as:

$$
M(\mathrm{t})=1-\exp \left(\frac{t-0.877}{12.836}\right)^{1.046}
$$

Using Eq. (10), the MTTR of DT.7 will be equal to 13.5 hours.

Table 3: The result of GOF analysis for DT.7

\begin{tabular}{|c|c|c|c|c|}
\hline \multirow{2}{*}{ Distribution } & \multicolumn{3}{|c|}{ Goodness of Fit Test } & \multirow{2}{*}{ Parameters } \\
\cline { 2 - 4 } & AvGOF & AvPLOT & LKV & \\
\hline 3P-Weibull & 99.9827 & 6.1446 & -318.8260 & Beta=1.046; Eta=12.836; Gamma=0.877 \\
\hline 2P-Exponential & 99.9974 & 10.1770 & -343.8620 & Lambda=5.7E-02; Gamma=-4.097 \\
\hline 1P-Exponential & 99.9986 & 9.1357 & -323.1657 & Lambda=0.058 \\
\hline 2P-Weibull & 99.9994 & 79.7068 & -349.1245 & Beta=1.418; Eta=13.232 \\
\hline Normal & 99.9999 & 12.9616 & -384.6652 & Mean=14.898; Std=15.220 \\
\hline
\end{tabular}

The repair rates for DT.7 in both models (MFM and classical distribution) are compared in Figure 2. There is a significant difference between the repair rates of DT.7 using these two models. In other words, observed and unobserved covariates have a significant effect on the repair rates of trucks; ignoring this factor may mislead a further decision on the operation and maintenance strategy. For example, according to the MFM, the repair rate of DT.7 after 10 hours will be equal to 0.12 , while using the classical approaches, and equal to 0.2 using MFM. Moreover, using MFM for maintainability analysis, we will obtain more information regarding the influencing factors. This information will help managers and decision-makers establish a more effective maintenance plan. For example, we know that the involved maintenance crew will decrease DT.7's repair rate by $90 \%$. Hence, in critical situations, increasing the number of involved maintenance crews can significantly increase the availability of DT.7. 


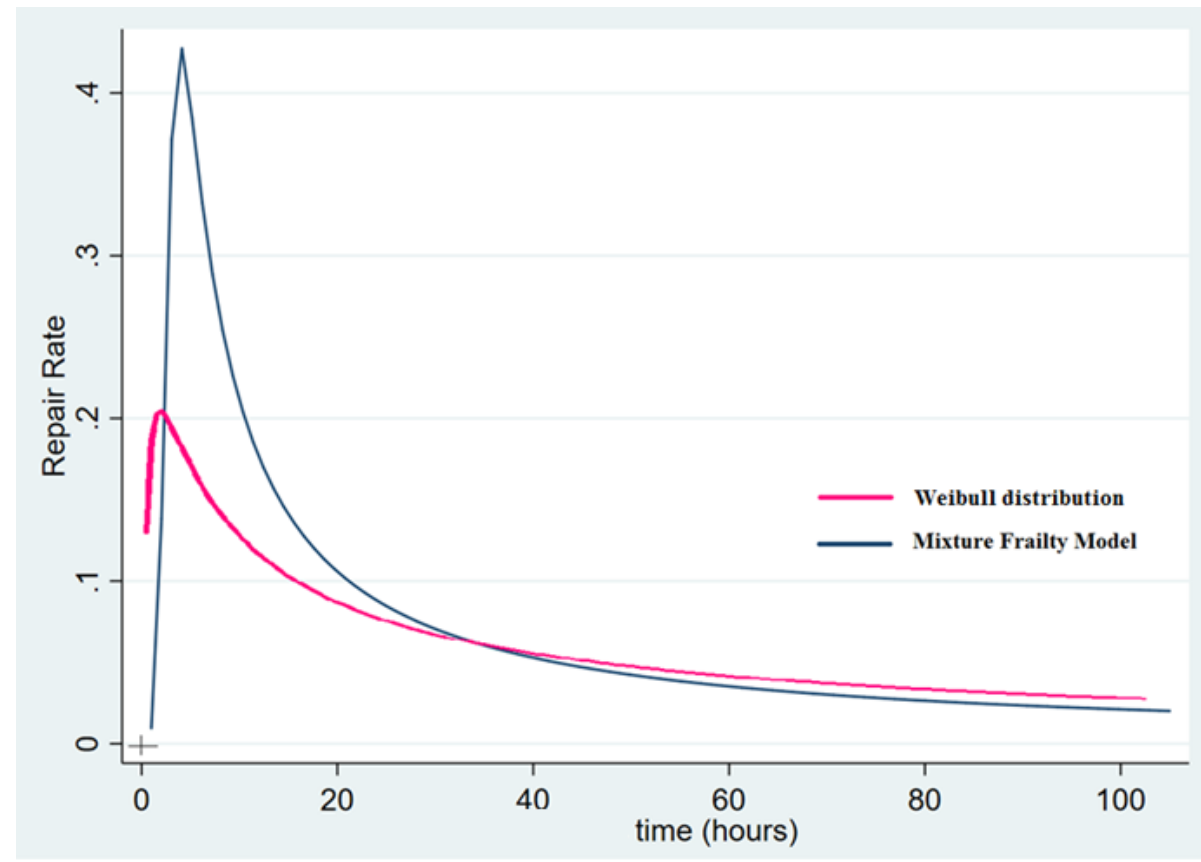

Figure 2: Repair rate of DT.7, using MFM approach and 3P Weibull distribution

\section{CONCLUSION}

The existing studies regarding the analysis of historical repair data have mostly ignored the effect of observed and unobserved covariates. As observed and unobserved covariates result in heterogeneity in repair data, the selected model should be able to capture the effects of both types of covariates.

In this paper, the application of MFM for maintainability analysis has been discussed. MFM has the ability to model the effect of observed and unobserved covariates on maintainability. Moreover, it can capture different repair processes in a single database, by the use of a convex combination of their associated distributions.

In the second part of the paper, the application of the developed model is illustrated by investigating the effect of observed and unobserved covariates on the maintainability of trucks at a copper mine. The results of analysis show that most identified observed covariates and unobserved covariate(s) have a significant effect on the maintainability of trucks. The results suggest that, in most cases, the baseline maintainability of trucks contains a mixture of different distributions. Finally, comparing the results of analysis using the MFM approach and classical distribution shows that ignoring the effects of observed and unobserved covariates can lead to significant deviation in the maintainability estimation. Such deviations may significantly affect any future operation and maintenance planning of the production process. 


\section{REFERENCES}

Aggarwal A, Kumar S, Singh V (2017) Performance modeling of the serial processes in refining system of a sugar plant using RAMD analysis. International Journal of System Assurance Engineering and Management 8:1910-1922. doi: 10.1007/s13198-016-0496-1

Ahmadzadeh F, Lundberg J (2014) Remaining useful life estimation: review. International Journal of System Assurance Engineering and Management 5:461-474. doi: 10.1007/s13198-013-0195-0

Asfaw ZG, Lindqvist BH (2015) Unobserved heterogeneity in the power law nonhomogeneous Poisson process. Reliability Engineering \& System Safety 134:59-65

Ayele Y, Barabadi A, Fuqing Y (2018) Mixture Lognormal Cox Regression Repair Model for Prediction of the Repair Time. IEEE, pp 1155-1159

Ayele YZ, Barabadi A, Barabady J (2016) Dynamic spare parts transportation model for Arctic production facility. International Journal of System Assurance Engineering and Management 7:84-98. doi: 10.1007/s13198-015-0379-x

Barabadi A, Barabady J, Markeset T (2010) Application of accelerated failure model for the oil and gas industry in Arctic region. IEEE, pp 2244-2248

Barabadi A, Barabady J, Markeset T (2011) Maintainability analysis considering time-dependent and time-independent covariates. Reliability Engineering \& System Safety 96:210-217

Barabadi A, Garmabaki A, Zaki R (2016) Designing for performability: An icing risk index for Arctic offshore. Cold Regions Science and Technology 124:77-86

Barabadi A, Gudmestad OT, Barabady J (2015) RAMS data collection under Arctic conditions. Reliability Engineering \& System Safety 135:92-99. doi: 10.1016/j.ress.2014.11.008

Barabadi A, Markeset T (2011) Reliability and maintainability performance under Arctic conditions. International Journal of System Assurance Engineering and Management 2:205-217

Cha JH, Finkelstein M (2014) Some notes on unobserved parameters (frailties) in reliability modeling. Reliability Engineering \& System Safety 123:99-103. doi: 10.1016/j.ress.2013.10.008

Clayton DG (1978) A model for association in bivariate life tables and its application in epidemiological studies of familial tendency in chronic disease incidence. Biometrika 65:141-151

Finkelstein M (2007) Shocks in homogeneous and heterogeneous populations. Reliability Engineering \& System Safety 92:569-574 
Furuly S, Barabadi A, Barabady J (2013) Reliability analysis of mining equipment considering operational environments: a case study. International Journal of Performability Engineering 9:287-294

Gao X, Barabady J, Markeset T (2010) An approach for prediction of petroleum production facility performance considering Arctic influence factors. Reliability Engineering \& System Safety 95:837-846

Garmabaki A, Ahmadi A, Ahmadi M (2016a) Maintenance optimization using multi-attribute utility theory. In: Current trends in reliability, availability, maintainability and safety. Springer, pp 1325

Garmabaki A, Ahmadi A, Block J, et al (2016b) A reliability decision framework for multiple repairable units. Reliability Engineering \& System Safety 150:78-88. doi: 10.1016/j.ress.2016.01.020

Garmabaki AHS, Ahmadi A, Mahmood YA, Barabadi A (2016c) Reliability Modelling of Multiple Repairable Units. Quality and Reliability Engineering International 32:2329-2343. doi: 10.1002/qre. 1938

Gharahasanlou AN, Ataei M, Khalokakaie R, et al (2017) Risk based maintenance strategy: a quantitative approach based on time-to-failure model. International Journal of System Assurance Engineering and Management 1-10. doi: 10.1007/s13198-017-0607-7

Gimenez O, Cam E, Gaillard J-M (2018) Individual heterogeneity and capture-recapture models: what, why and how? Oikos 127:664-686. doi: 10.1111/oik.04532

Giorgio M, Guida M, Pulcini G (2014) Repairable system analysis in presence of covariates and random effects. Reliability Engineering \& System Safety 131:271-281. doi: 10.1016/j.ress.2014.04.009

Gudmestad OT, Markeset T (2015) Oil and gas operations under extreme conditions in the cold north. International Journal of Computational Methods and Experimental Measurements 3:7-12

Hoseinie SH, Ataei M, Khalokakaie R, Kumar U (2011) Reliability and maintainability analysis of electrical system of drum shearers. Journal of Coal Science and Engineering (China) 17:192-197. doi: $10.1007 / \mathrm{s} 12404-011-0216-\mathrm{Z}$

Hougaard P (1995) Frailty models for survival data. Lifetime Data Analysis 1:255-273. doi: 10.1007/BF00985760

Knezevic J (1993) Reliability, maintainability, and supportability: a probabilistic approach. McGraw-Hill Companies

Kumar D, Klefsjö B (1994) Proportional hazards model: a review. Reliability Engineering \& System Safety 44:177-188 
Kumar L, Kumar M, Rath S (2017) Maintainability prediction of web service using support vector machine with various kernel methods. International Journal of System Assurance Engineering and Management 8:205-222. doi: 10.1007/s13198-016-0415-5

Naseri M, Barabady J (2016) On RAM performance of production facilities operating under the Barents Sea harsh environmental conditions. International Journal of System Assurance Engineering and Management 7:273-298. doi: 10.1007/s13198-016-0463-x

Patel K, Kay R, Rowell L (2006) Comparing proportional hazards and accelerated failure time models: an application in influenza. Pharmaceutical Statistics 5:213-224. doi: 10.1002/pst.213

Rausand M, Høyland A (2004) System reliability theory: models, statistical methods, and applications. John Wiley \& Sons

Rosen O, Tanner M (1999) Mixtures of proportional hazards regression models. Statistics in Medicine 18:1119-1131. doi: 10.1002/(SICI)1097-0258(19990515)18:9<1119::AID-SIM116>3.0.CO;2-V

Sellitto MA, Brusius Jr W (2017) Maintenance strategy based on reliability analytical models for three parallel mechanical transformation machines. IEEE Latin America Transactions 15:988-993

Slimacek V, Lindqvist BH (2016) Reliability of wind turbines modeled by a Poisson process with covariates, unobserved heterogeneity and seasonality. Wind Energy 19:1991-2002. doi: 10.1002/we. 1964

Slimacek V, Lindqvist BH (2017) Nonhomogeneous Poisson process with nonparametric frailty and covariates. Reliability Engineering \& System Safety 167:75-83. doi: 10.1016/j.ress.2017.05.026

Tortorella M (2015) Reliability, maintainability, and supportability: best practices for systems engineers. John Wiley \& Sons

Tsarouhas P (2018) Reliability, availability and maintainability (RAM) analysis for wine packaging production line. International Journal of Quality \& Reliability Management 35:821-842

Tsarouhas PH (2015) Maintainability analysis in the yogurt industry. International Journal of System Assurance Engineering and Management 6:119-128. doi: 10.1007/s13198-014-0254-1

Tsarouhas PH, Arvanitoyannis IS (2012) Reliability and maintainability analysis to improve the operation of the limoncello production line. International Journal of Food Science \& Technology 47:16691675

Tsarouhas PH, Arvanitoyannis IS, Ampatzis ZD (2009) A case study of investigating reliability and maintainability in a Greek juice bottling medium size enterprise (MSE). Journal of Food Engineering 95:479-488 
Van Horenbeek A, Pintelon L, Muchiri P (2010) Maintenance optimization models and criteria. International Journal of System Assurance Engineering and Management 1:189-200. doi: 10.1007/s13198-011-0045-x

Vaupel JW, Manton KG, Stallard E (1979) The impact of heterogeneity in individual frailty on the dynamics of mortality. Demography 16:439-454

Wang J (2014) Proceedings of the First Symposium on Aviation Maintenance and Management-Volume II. Springer Science \& Business Media

Wijaya AR, Lundberg J (2012) The effect of the operator, the mine room and their interaction on the measured vibration level of a scaling machine. International Journal of System Assurance Engineering and Management 3:145-152. doi: 10.1007/s13198-012-0096-7 